\title{
Formulation and Evaluation of Sodium Alginate and Guar Gum Based Glycyrrhizin Loaded Mucoadhesive Microspheres for Management of Peptic Ulcer
}

\author{
Ranjit Kumar Harwansh*, Rohitas Deshmukh \\ Institute of Pharmaceutical Research, GLA University, Mathura, Uttar Pradesh, INDIA.
}

\begin{abstract}
Background: Glycyrrhizin (GZ) is a bioactive ingredient of Glycyrrhiza glabra, reported for various therapeutic effects including gastro-protection. It has been associated with low absorption, early elimination, short half-life and poor bioavailability. Objectives: Aim of the current study was to formulate GZ loaded mucoadhesive microspheres by using mucopolymers like sodium alginate and guar gum for the management of peptic ulcer. Methods: Various GZ loaded microspheres (GZ-MS1-3) were prepared by an emulsification-crosslinking technique. These formulations were developed with different proportions of guar gum and sodium alginate. The formulations were characterized and evaluated by various parameters including particle size, zeta potential, entrapment efficiency (\% EE), \% yield, SEM, FTIR, swelling index, mucoadhesive efficiency, in vitro drug release and in vivo antioxidant activities. Results: Result stated that suitable particle size $(50.18 \pm 1.15 \mu \mathrm{m})$, zeta potential $(-31.12 \pm 2.16 \mathrm{mV}), \% \mathrm{EE}(92.67 \pm 1.91)$ and $\%$ yield $(97.45 \pm 1.83)$ was achieved with optimized formulation, GZ-MS1. Significant $\left({ }^{* *} P<0.001\right)$ swelling index $(0.94 \pm 0.04)$ and mucoadhesive efficiency $(95.98 \pm$ $3.62 \%)$ was obtained with GZ-MS1. GZ-MS1 showed maximum drug release profile $(94.57 \pm 4.03 \%)$ in simulated gastric fluid (SGF, pH 1.2) at $37 \pm 0.5^{\circ} \mathrm{C}$ for $24 \mathrm{~h}$. FTIR study confirmed that there was no interaction observed between $G Z$ and excipients. Conclusion: Sustained release profile of the optimized formulation was achieved due to significant mucoadhesive efficiency of the sodium alginate and guar gum. Thus, the mucoadhesive microspheres of $\mathrm{GZ}$ would be an effective strategy for the management of peptic ulcer.
\end{abstract}

Key words: Mucoadhesive microspheres, Glycyrrhizin, Mucopolymers, Sodium alginate, Guar gum, Sustained release, Peptic ulcer.

\section{INTRODUCTION}

Peptic Ulcer (PU) is a multifactorial gastrointestinal tract disease, concerned with open sores or lesions in the mucosal lining of the stomach and duodenum. Most of the people have suffered with PU globally. PU has been connected with indigestion, nausea, heartburn, dyspepsia, bleeding and epigastric pain. ${ }^{1,2}$ Helicobacter pylori infection and use of nonsteroidal anti-inflammatory drugs (NSAIDs) are the main factors for causing PU. ${ }^{3,4}$ The inflammatory cytokines like IL-17A, IL-8 IL-1 $\beta$ and TNF- $\alpha$ are responsible for the pathogenesis of $\mathrm{PU}$ in humans and considered as major factors for prevalence of PU in developing countries. ${ }^{5,6}$ There are numerous classes of modern therapy available for the management of PU which include antibiotics, antacids, anticholinergics, antisecretory agents (proton pump $\mathrm{H}^{+} / \mathrm{K}^{+}$ATPase inhibitors), cytoprotective agents and antihistaminics $\left(\mathrm{H}_{2}\right.$ receptor antagonist). ${ }^{7}$ But their therapeutic uses are limited due to side effects, the incidence of relapses and multidrug resistance. Thus, herbal medicine can be used as a safe and alternative drug for the treatment of PU. A wide array of botanicals
Submission Date: 30-12-2020; Revision Date: 12-03-2021; Accepted Date: 03-05-2021

DOI: 10.5530/ijper.55.3.145 Correspondence:

Dr. Rohitas Deshmukh, Associate Professor, Institute of Pharmaceutical Research, GLA University, Mathura-281406, Uttar Pradesh, INDIA.

Phone: +91-7724847691 Email id: rahi18rahi@gmail. com

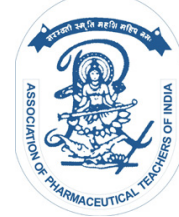

www.ijper.org 
and their bioactive phytoconstituents have potential to treat several kinds of diseases like PU. ${ }^{3}$ GZ is a potent bioactive of Glycyrrbiza glabra, reported to be antiulcer, antiinflammatory, antioxidant, antibacterial, anticancer, hepatoprotective and antiviral. GZ is a BCS-II molecule and its therapeutic activities are limited due to poor absorption (log p 2.8), lowest bioavailability $(\sim 1 \%)$ and low half-life $(3.5 \mathrm{~h}){ }^{8-11} \mathrm{GZ}$ possessed its potent antiinflammatory activity through selective inhibition of prostaglandin E2, cyclooxygenase, lipoxygenase and phospholipase A2. ${ }^{12}$

The novel oral mucoadhesive drug delivery system has the ability of retaining in the stomach for longer times and can release the drug content slowly so that an effective level of drug can be provided to its site of absorption (stomach) to heal the ulcer. Moreover, these systems can channel the local drug action in the upper region of the small intestine, which can be suitable for the treatment of duodenal ulcer as well (Figure 1). It is utmost important in drug delivery system to meet the current demand of drug therapy by maintaining drug concentration in blood circulation for prolonged times. ${ }^{13-15}$

Mucoadhesive microspheres are tiny spherical units $(\sim 1000 \mu \mathrm{m})$, have the ability to form bioadhesion to the gastric mucosa which restricts gastric emptying of formulation through the pyloric sphincter. These carrier systems can be spread out homogeneously over the entire region of the stomach and upper small intestine, which can facilitate improved absorption and localized action of drug. ${ }^{16,17}$ The bioadhesion of these carriers are generally facilitated by muco-polymers, having the ability to adhere to the surface of epithelial tissues of the stomach by intimate contact. This results in delaying gastric emptying time, thus the time of retention of the product in the gastric region is enhanced. ${ }^{18}$

Sodium alginate (SA) is a polysaccharide type polymer (anionic in nature), used as a mucoadhesive and gelling agent in the development of microcarriers. It has two units, $\beta-1,4{ }_{D}-$ manurunic acid and $\alpha-1,4-_{L}$-guluronic acid in their structure that offers optimum mucoadhesive properties including $\mathrm{pH}$-sensitivity, cross-linking capability, biocompatibility and biodegradability. These features are more suitable for gastric delivery. ${ }^{19,20}$ Guar gum $(\mathrm{GG})$ is another plant derived mucopolymer having mannose $(1 \rightarrow 4)-\beta_{-}{ }_{D}$-mannopyranosyl and galactose $\alpha^{-}{ }_{D}{ }^{-}$ galactopyranosyl structural unit, joined through $(1 \rightarrow 0)$ bond. It is having amazing gelling, mucoadhesive and biodegradable property. ${ }^{21,22}$ Thus, the current study was aimed to prepare SA-GG based glycyrrhizinmucoadhesive microspheres for gastric delivery.

\section{MATERIALS AND METHODS}

\section{Materials}

The pure GZ (assay 99\%) was purchased from Sigma Chemicals, Germany. SA and GG were purchased from Finar Chemicals Ltd., Ahmedabad, India. Castor oil and Span 80 was obtained from Merck, Mumbai, India. Analytical grade other chemicals, reagents and deionised water were used in the experiment.

\section{Preparation of Standard Solution of Glycyrrhizin}

SGF ( $\mathrm{pH} 1.2$ ) was prepared by incorporation of $\mathrm{HCl}$ $(7 \mathrm{~mL}), \mathrm{NaCl}(2 \mathrm{~g})$ and pepsin $(3.2 \mathrm{~g})$ in distilled water $(1000 \mathrm{~mL})$. The accurate amount of GZ $(10 \mathrm{mg})$ was transferred into a volumetric flask $(100 \mathrm{~mL})$, then the volume was adjusted up to the mark by SGF to get a final concentration of $100 \mu \mathrm{g} / \mathrm{mL}$. It was considered as a stock to prepare aliquots further.

\section{Preparation of Different Aliquots of Glycyrrhizin}

UV-spectrophotometer, Shimadzu 1700, Japan was used for analysis of the sample. From the standard stock solution, different aliquots $0.2,0.4,0.6,0.8,1.0,1.2,1.4$, $1.6,1.8,2.0,2.2$ and $2.4 \mathrm{~mL}$ were taken and diluted to get concentration of $2-24 \mu \mathrm{g} / \mathrm{mL}$ respectively. These solutions were passed through the syringe filter and absorbance of each sample was recorded at $258 \mathrm{~nm}$ by UV-spectrophotometer.

\section{Preparation of Glycyrrhizin Loaded Mucoadhesive Microspheres}

GZ unloaded and loaded mucoadhesive microspheres (GZ-MS) were fabricated by modified emulsificationcrosslinking method (Figure 2). ${ }^{21}$ Briefly, GZ (200 mg) was dissolved in $100 \mathrm{~g}$ deionised water containing tween $80(1 \%, w / w)$. A polymer dispersion system composed

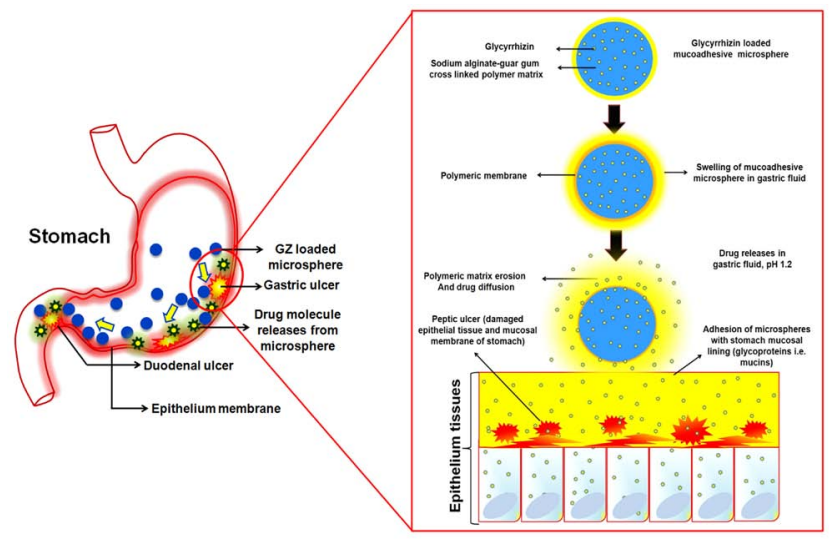

Figure 1: Schematic representation of peptic ulcer (gastric ulcer and duodenal ulcer) and glycyrrhizin loaded mucoadhesive microsphere based treatment approach for the peptic ulcer 
of sodium alginate $(1.5-2.5 \%, \mathrm{w} / \mathrm{w})$ and guar gum $(500$, 600 and $700 \mathrm{mg}$ ) in distilled water (100 g), was utilized for preparation of GZ-MS. To get a homogeneous mass, these dispersions were allowed to swell completely at room temperature for $2 \mathrm{~h}$ and mixed by digital magnetic stirrer (Remi, India). The ratio between GZ and polymers was 1:10, 1:13 and 1:16 w/w (Table 1). Then polymer dispersion was added dropwise into the dispersion medium (castor oil containing span 80, concentrated sulfuric acid and glutaraldehyde) by syringeneedle (24 G size). It was stirred at a constant speed of $3000 \mathrm{rpm}$ for $4 \mathrm{~h}$ at $50^{\circ} \mathrm{C}$ to produce microspheres. The formed microspheres were filtered and washed with isopropyl alcohol. Sodium bisulfite was used to remove the glutaraldehyde residue in the formulations. The microspheres were dried at $50^{\circ} \mathrm{C}$ under a hot air oven and kept for $24 \mathrm{~h}$ in vacuum desiccators till further studies.

\section{Characterization and Evaluation of Mucoadhesive Microspheres of Glycyrrhizin}

Particle Size, Polydispersity Index (PDI) and Zeta Potential Analysis

The average particle size, PDI and zeta potential of suspended mucoadhesive microspheres (GZ-MS1-3, $10 \mathrm{mg} / \mathrm{mL}$ ) were analyzed by Zetasizer (Nano ZS90, Malvern instruments Ltd., UK) with a $50 \mathrm{mV}$ laser. Analysis was performed at room temperature $(25 \pm$ $\left.0.5^{\circ} \mathrm{C}\right)$.

\section{Percentage Yield and Entrapment Efficiency (\%EE)}

$\%$ Yield and \%EE of the GZ loaded mucoadhesive microspheres (GZ-MS1-3) were determined as per our previous reported method. ${ }^{23}$ Sample was analyzed through UV-spectrophotometer (Shimadzu 1700, Japan) at $258 \mathrm{~nm}$.

Percentage (\%) yields of different formulations, GZ-MS1-3 were calculated by the following formula.

$\%$ Yield $=$ (Weight of microspheres $/$ Weight of all nonvolatile components) $\times 100 \ldots \ldots$ (1)

$\%$ EE of the glycyrrhizin loaded mucoadhesive microspheres (GZ-MS1-3) were determined as per the reported method. ${ }^{23}$ Briefly, specific weight $(100 \mathrm{mg})$ of microspheres was crushed in a glass mortar to make powder. Then it was transferred into a volumetric flask containing SGF $(100 \mathrm{~mL})$ and ultrasonicated to extract out the drug content in the medium. Thereafter, the suspension was filtered through membrane filters $(0.45$ $\mu \mathrm{m})$ and analyzed through a UV-spectrophotometer (Shimadzu 1700, Japan) at $258 \mathrm{~nm}$. Each determination was made in triplicate $(n=3)$. The $\% \mathrm{EE}$ was estimated based on the following formula.

$\% \mathrm{EE}=$ (Actual drug content $/$ Theoretical drug content $)$ $\times 100$

\section{Degree of Swelling}

The swelling degree of GZ-MS1-3 was performed in SGF medium ( $\mathrm{pH} 1.2$ ) to ensure their swelling ability. ${ }^{23}$ USP type 1 (basket type) dissolution test apparatus was utilized to carry out the swelling degree of the formulations in SGF at $37 \pm 0.1^{\circ} \mathrm{C}$. An appropriate amount of sample (100 mg) was transferred into the basket and allowed to swell for $12 \mathrm{~h}$. Then the wet microspheres were taken out and treated with blotting paper to remove excess SGF drops from the surface of the microspheres. The weight of the wet microspheres was recorded and their swelling property was calculated from the following formula.

Degree of swelling $(\alpha)=\omega_{\mathrm{s}}-\omega_{\mathrm{o}}, \omega_{0} \ldots \ldots \ldots \ldots$ (3)

Where, $\omega_{0}=$ weight of microspheres before swelling and $\omega_{\mathrm{s}}=$ weight of microspheres after swelling.

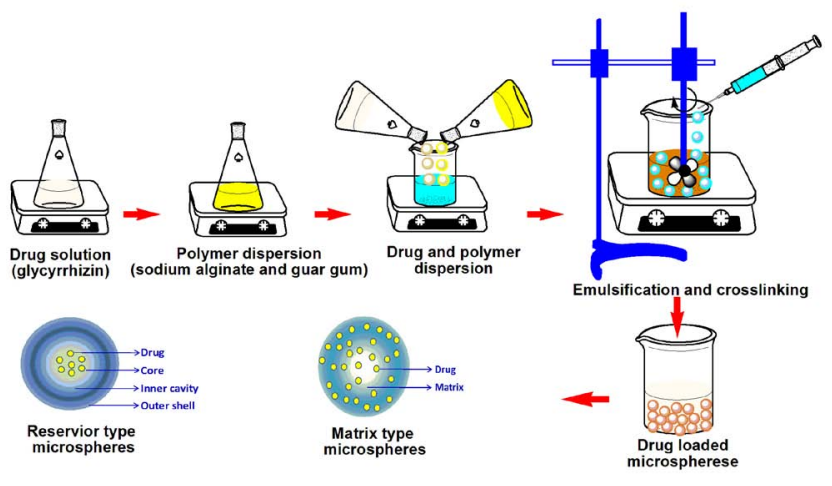

Figure 2: Schematics of preparation of glycyrrhizin loaded mucoadhesive microspheres.

\begin{tabular}{|c|c|c|c|c|}
\hline \multicolumn{2}{|c|}{ Table 1: Formulation of glycyrrhizin loaded different mucoadhesive microspheres. } \\
\hline \multirow{2}{*}{ Formulation } & $\begin{array}{c}\text { Drug : } \\
\text { Polymer ratio }\end{array}$ & $\begin{array}{c}\text { Glycyrrhizin } \\
\text { (mg, w/w) }\end{array}$ & $\begin{array}{c}\text { Polymers } \\
\text { Guar gum } \\
\text { (mg, w/w) }\end{array}$ & $\begin{array}{c}\text { Sodium alginate } \\
\text { (mg, w/w) }\end{array}$ \\
\hline GZ-MS1 & $1: 10$ & 200 & 500 & 1500 \\
\hline GZ-MS2 & $1: 13$ & 200 & 600 & 2000 \\
\hline GZ-MS3 & $1: 16$ & 200 & 700 & 2500 \\
\hline
\end{tabular}


In vitro Mucoadhesiveness of Glycyrrhizin Loaded Formulations

The mucoadhesive properties of GZ-MS1-3 were studied through modified in vitro wash-off technique. ${ }^{24}$ Briefly, freshly excised pieces of goat stomach (collected from a local slaughter house) were fixed on a glass slide $(7.5 \times 2.5 \mathrm{~cm})$ with the help of dual adhesive tape. The USP tablet disintegration test apparatus was used to perform this study. Measured number of microspheres were put over the mucosal layer of slides and attached in to a arm of the apparatus. Then, they were placed into a $900 \mathrm{~mL}$ beaker (SGF, $\mathrm{pH} 1.2,37 \pm 0.5^{\circ} \mathrm{C}$ ) and movement (up and down) of the was maintained for $12 \mathrm{~h}$. The \% mucoadhesiveness of the GZ-MS1-3 was noted at different time intervals and measured by the following formula.

$\%$ Mucoadhesiveness $=$ Quantity of microspheres adhered / Quantity of microspheres spread $\times 100$ (4)

\section{In vitro Drug Release Study}

In vitro drug release studies of GZ-MS1-3 were performed in SGF ( $\mathrm{pH}$ 1.2) by using a single dissolution test (paddle type) apparatus. Different formulations (GZ-MS1-3, $100 \mathrm{mg}$ ) were spread gently over the surface of the beaker containing $900 \mathrm{~mL}$ SGF buffer medium $\left(37 \pm 0.5^{\circ} \mathrm{C}\right)$ and it was agitated at $100 \mathrm{rpm}$ for $24 \mathrm{~h}$. The sink condition was maintained throughout the study by withdrawing $5 \mathrm{~mL}$ of sample and replacing with the equivalent volume of fresh dissolution medium. Samples were filtered with the help of a $0.45 \mu \mathrm{m}$ syringe filter and analyzed by spectrophotometer at $258 \mathrm{~nm}$. GZ concentrations in different samples were calculated based on a standard calibration curve. All experiments were performed in triplicate $(n=3)$.

\section{Spectrophotometric Analysis}

Pure GZ (10 mg) was poured into different volumetric flasks. Different excipients like sodium alginate (10 $\mathrm{mg})$ and guar gum $(10 \mathrm{mg})$ were added into flasks and volume was adjusted up to $10 \mathrm{ml}$ with SGF ( $\mathrm{pH} 1.2$ ) then flasks were agitated for $6 \mathrm{~h}$ and stored overnight. Samples were filtered, suitably diluted and analyzed at $258 \mathrm{~nm}$ by UV-spectrophotometer.

\section{Fourier Transforms Infrared (FTIR)}

The FTIR spectrum investigation was carried out to confirm the compatibility of pure glycyrrhizin with different excipients which was used for preparation of optimized mucoadhesive microspheres (GZ-MS1). The $\mathrm{KBr}$ discs of individual ingredients, i.e. pure glycyrrhizin, GZ-MS1, sodium alginate and guar gum were prepared and analysed by using a FTIR spectrophotometer (Perkin Elmer, USA) in the range of $4000-500 \mathrm{~cm}^{-1}$.

\section{Surface Electron Microscopy (SEM)}

The shape and surface morphology of optimized formulation (GZ-MS1) and placebo GZ-MS1 was studied by using SEM (Jeol JSM-1600, Tokyo, Japan). Briefly, aluminum stub and double-sided adhesive carbon tape were used for preparation of samples. Formulations were sprinkled over the surface of the tape containing stub for sampling. Sample coating material, platinum was applied to make a fine layer $(300$ ${ }^{\circ}$ A thickness) onto the specimen-stub by using sputtercoater under argon atmosphere and high-vacuum condition. These specimens were analysed by SEM and their photomicrographs were recorded at different magnifications.

\section{Drug Release Kinetic Models}

Various drug release kinetic models including Zero order, First order, Higuchi's and Korsmeyer-Peppas were subjected for formulations, GZ-MS1-3 to forecast their mechanism of drug release.

\section{Stability Analysis}

GZ-MS1 was subjected for stability study at various conditions of $25 \pm 2^{\circ} \mathrm{C} / 60 \pm 5 \% \mathrm{RH}, 30 \pm 2^{\circ} \mathrm{C} / 65 \pm$ $5 \% \mathrm{RH}$ and $40 \pm 2{ }^{\circ} \mathrm{C} / 75 \pm 5 \% \mathrm{RH}$ according to the guideline of ICH. Briefly, prior analysis, product (GZ-MS1) was stored in a tightly closed container (amber colored glass bottles). Then, the product was kept in a chamber of stability testing equipment where modulated environmental conditions were provided for a period of 180 days. The formulations were observed for changes in their morphological behaviour, particle size, zeta potential, physical appearance and drug content at an interval of 45, 90 and 180 days.

\section{Evaluation of Antioxidant Potential of GZ-Loaded Formulations against Ethanol Mediated Gastric Damages}

\section{Animals}

Male Wistar rats ( $200 \mathrm{~g}$ ) were used in this experiment, animals were stored in 5 groups $(\mathrm{n}=6)$ in different cages and acclimatized at room temperature $\left(25 \pm 0.5^{\circ} \mathrm{C}\right.$ and $45-55 \% \mathrm{RH}$ ) for 1 week with $12 \mathrm{~h}$ light/dark cycles. All animals had free access to feed and purified water. The experimental protocol was approved by the Institutional Animal Ethics Committee.

\section{Dosing}

Antioxidant potential of GZ and GZ-MS1 were performed as the reported method. ${ }^{25}$ Prior to the 
experiment, all the rats were fasted for overnight with free access to water. Animals were divided into following different groups like group I: normal control $(0.5 \%$ tween $80,5 \mathrm{~mL} / \mathrm{kg}$ body weight, p.o.), group II: disease control (1 mL/200 g ethanol, p.o.), group III: GZ200 (200 mg/kg GZ, p.o.), group IV: GZ-MS1 ( 200 mg/ $\mathrm{kg} \mathrm{GZ,} \mathrm{p.o.)} \mathrm{and} \mathrm{group} \mathrm{V:} \mathrm{placebo} \mathrm{(500} \mathrm{mg/kg,} \mathrm{p.o.).} \mathrm{An}$ ulcerogenic agent, absolute ethanol (95-99\%, $1 \mathrm{~mL} / 200$ g) was given orally to all animal groups except the normal group after $1 \mathrm{~h}$. All the rats were sacrificed and stomachs were removed after $1 \mathrm{~h}$ of ethanol administration. Glandular gastric tissues were dissected out and washed with ice-cold saline. These gastric tissues were homogenized into several fragments and homogenates were made in phosphate-buffer saline (0.1 M, pH 7.4). These homogenates were centrifuged at $13500 \mathrm{rpm}$ for 5 min using Spinwin MC-02, Tarson, India. Then pure supernatant layers of the homogenates were taken out and kept at $-20^{\circ} \mathrm{C}$ till further uses.

\section{Antioxidant Marker Enzymes Estimation in Rat Gastric Tissue}

Estimation of catalase (CAT) ${ }^{26}$ thiobarbituric acid reactive substances (TBARS), ${ }^{27}$ superoxide dismutase $(\mathrm{SOD})^{28}$ and glutathione peroxidase $(\mathrm{GPx})^{29}$ levels in rat stomach homogenate were carried out. In the rat gastric homogenate, the total content of protein was determined..$^{30}$ Protein content was estimated as units/ mg.

\section{Statistical Analysis}

One-way ANOVA-Dunnet's post hoc test was performed for statistical analysis of various experimental data. The data were processed through Graph Pad Prism, San Diego, CA, USA. Mean \pm SD and Mean \pm SEM were expressed for all data. The "P" value less than $0.05(P<$ $0.05)$ was considered to be significant throughout the statistical treatment.

\section{RESULTS}

\section{Characterization and Evaluation of Glycyrrhizin Loaded Mucoadhesive Microspheres}

\section{Particle Size, PDI and Zeta Potential Analysis}

The particle size, PDI and zeta potential of the GZ loaded mucoadhesive microsphere formulations (GZ-MS1-3) were analysed. The detail features of formulations were explained in Table 2. The particle size (Figure 3A), PDI and zeta potential (Figure 3B) were found to be $50.18 \pm$ $1.15 \mu \mathrm{m}, 0.62 \pm 0.11$ and $-31.15 \pm 2.16 \mathrm{mV}$ for GZ-MS1 respectively.

\section{\%Yield and \%Entrapment Efficiency}

\%Yield of the different formulations, GZ-MS1-3 was shown in Table 2 . The maximum yield $(97.45 \pm 1.83 \%)$ of the formulation was obtained with GZ-MS1. It may be due to an appropriate ratio of drug: polymer (1:10 $\mathrm{w} / \mathrm{w})$ for development of microspheres at a constant stirring rate $(3000 \mathrm{rpm}) . \% \mathrm{EE}$ of the GZ loaded various formulations (GZ-MS1-3) were represented in Table 2. GZ-MS1 showed maximum (92.67 $\pm 1.91 \%)$ entrapment efficiency which may be due to the suitable composition of SA-GG in the microspheres.

\section{Degree of Swelling and in vitro Mucoadhesiveness}

Swelling properties of different formulations were performed in SGF medium $(\mathrm{pH} 1.2)$ and results were represented in Figure 3C. Swelling degrees (a) were found to be in the range of $0.94 \pm 0.04$ to $0.62 \pm 0.04$ for GZ-MS1-3. The best swelling degree value $(0.94$ $\pm 0.04)$ was achieved with GZ-MS1 for an extended period $(12 \mathrm{~h})$, which may be suitable for retaining in the stomach. As a result, it was stated that the degree of swelling was higher for GZ-MS1 due to cross-linked polymers, SA-GG. Cross-linking of polymers with
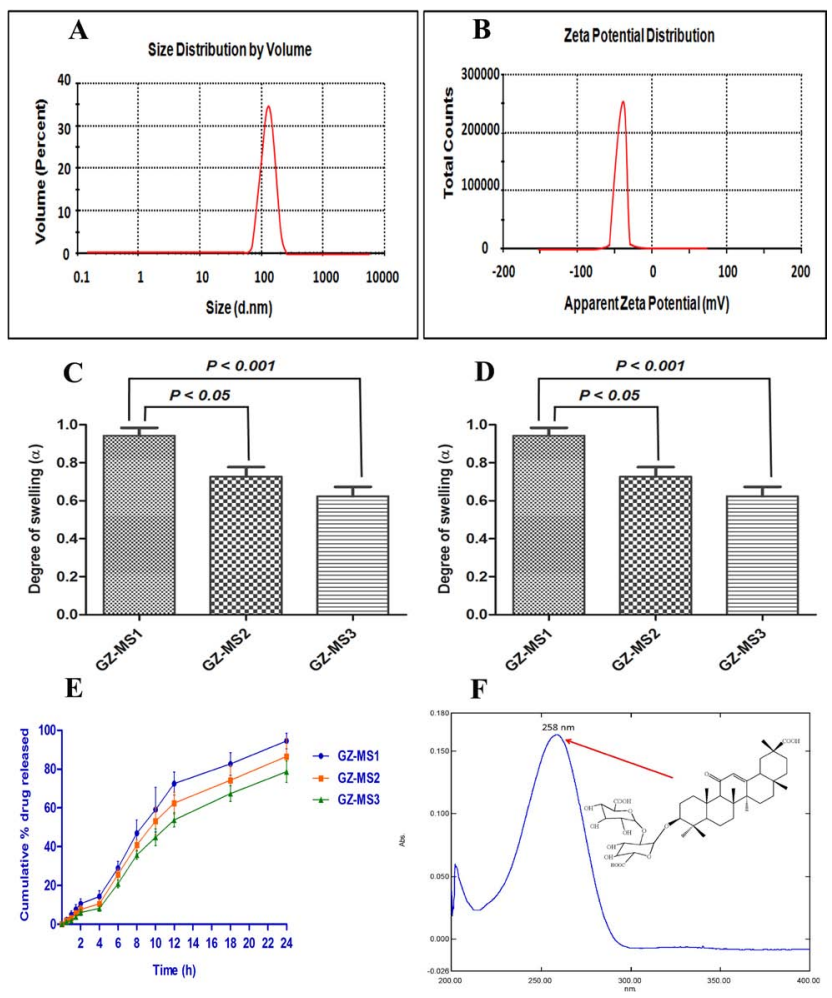

Figure 3: Particle size (A), zeta potential of GZ-MS1 (B), swelling degree (C), mucoadhesive properties (D), in vitro drug release profile $(E)$ of glycyrrhizin loaded microspheres (GZ-MS1-3) and UV-spectrum of pure glycyrrhizin in SGF buffer at $258 \mathrm{~nm}(\mathrm{~F})$. Values were Mean $\pm \mathrm{SD}(n=3) .{ }^{\star \star} P<0.05$ and ${ }^{* * *} P<0.001$. 
glutaraldehyde extended the swelling process in SGF and in vitro digestion of the GZ-microspheres.

Mucoadhesive behaviors of various formulations, GZ-MS1-3 were performed to check out the adhesion efficiency of microspheres to the gastric mucosa for prolonged drug release. Results have been shown in Figure 3D. Mucoadhesive characteristics were found to be $95.98 \pm 3.62$ to $66.28 \pm 4.48 \%$ for different formulations (GZ-MS1-3). The highest mucoadhesive behaviour (95.98 $\pm 3.62 \%)$ was achieved with GZ-MS1. This may be due to mucoadhesive affinity of the crosslinked SA-GG towards the gastric mucosal membrane containing glycoproteins.

\section{In vitro Drug Release Study}

GZ release profiles of different formulations, GZ-MS1-3 were studied in SGF dissolution medium ( $\mathrm{pH}$ 1.2) at $37^{\circ} \mathrm{C}$. Drug release profile was recorded in the range of $94.57 \pm 4.03$ to $78.73 \pm 5.51 \%$ for GZ-MS1-3 respectively. The maximum GZ was found to be 94.57 $\pm 4.03 \%$ with GZ-MS1 for an extended period of 24 $\mathrm{h}$ as compared with other formulations. Detailed in vitro drug release profiles of different formulations were represented in Figure 3E.

\section{Spectrophotometric Analysis}

UV-spectrum analysis of the GZ and along with their formulation excipients were shown in Figure 3F. The wavelength of the GZ-sodium alginate, GZ-guar gum or in combination was the same as pure GZ $(258 \mathrm{~nm})$ when assayed spectrophotometrically. This indicates that there were no significant interactions seen between polymers and GZ used in the formulations.

\section{FTIR}

FTIR analysis was performed to check the drugexcipient compatibility and detailed FTIR spectrum of GZ, GZ-MS1, SA and GG was shown in Figure 4(A-D). Spectrum of GZ showed prominent $-\mathrm{OH}$ stretching band at $3223.05 \mathrm{~cm}^{-1}$, C-H stretching band at $2947.23 \mathrm{~cm}^{-1}, 2875.86 \mathrm{~cm}^{-1}$ and $-\mathrm{C}=\mathrm{O}$ stretching peak at $1722.43 \mathrm{~cm}^{-1}, \mathrm{C}=\mathrm{C}$ stretching vibration at 1656.85 $\mathrm{cm}^{-1}$, C-H deformation at $1452.04 \mathrm{~cm}^{-1}$ and $\mathrm{C}-\mathrm{OH}$ stretching at $1053.13 \mathrm{~cm}^{-1}$. But in the case of GZ-MS1, these bands were slightly shifted due to entrapment GZ in the polymer matrix. Thus, the FTIR spectrum confirmed the presence of GZ in the formulation and it suggested that the excipients used in the development of the mucoadhesive microspheres were compatible with GZ. No drug-excipient interactions were seen in the formulation.

\section{SEM}

Surface structure and morphology of the optimized formulation, GZ-MS1 and placebo were shown in Figure 5(A-D). Photomicrographs of samples demonstrated that the particles were spherical and normal in shape at 400x magnifications. However, rough surface and matrix structure of both the formulations were observed at high magnification $(1500 \mathrm{x})$ this could be due to the crosslinking of SA and GG.

\section{Drug Release Kinetics}

In vitro release data of GZ-MS1-3 were analysed with various kinetic models like Zero order, First order,

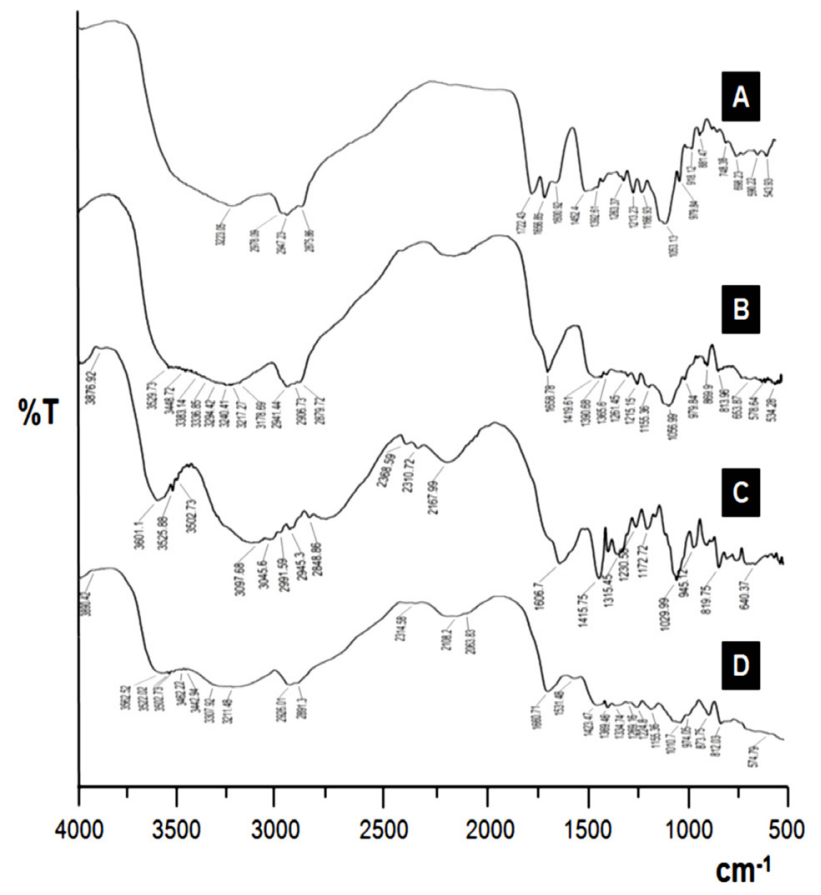

Figure 4: FTIR spectrum of pure glycyrrhizin (A), GZ-MS1 (B), sodium alginate (C) and guar gum (D).

\begin{tabular}{|c|c|c|c|c|c|}
\hline \multicolumn{6}{|c|}{ Table 2: Characterization of GZ loaded different mucoadhesive microspheres. } \\
\hline Formulations & $\begin{array}{c}\text { Particle size } \\
(\boldsymbol{\mu m})\end{array}$ & PDI & $\begin{array}{c}\text { Zeta potential } \\
(\mathrm{mV})\end{array}$ & \%Yield & \%EE \\
\hline GZ-MS1 & $50.18 \pm 1.15$ & $0.62 \pm 0.11$ & $-31.12 \pm 2.16$ & $97.45 \pm 1.83$ & $92.67 \pm 1.91$ \\
\hline GZ-MS2 & $57.21 \pm 1.80$ & $0.74 \pm 0.23$ & $-33.15 \pm 2.67$ & $91.30 \pm 2.44$ & $87.32 \pm 2.13$ \\
\hline GZ-MS3 & $64.12 \pm 2.18$ & $0.68 \pm 0.32$ & $-36.10 \pm 3.14$ & $85.12 \pm 2.90$ & $83.43 \pm 2.65$ \\
\hline
\end{tabular}

Where, PDI: Polydispersity index; \%EE: Percentage drug entrapment efficiency.Values were represented as (Mean \pm SD) $(n=3)$. 
Higuchi's and Korsmeyer-Peppas to predict their release behaviour. Results of kinetic models of GZ-MS1-3 were given in Table 3. The best fit kinetics, such as Higuchi square root $\left(r^{2}=0.941\right)$ and Korsmeyer-Peppas $\left(R^{2}\right.$ $=0.907)$ were achieved with GZ-MS1. In KorsmeyerPeppas model, GZ-MS1 showed $(n=1.127)$ diffusion exponent as compared to the other formulations.

\section{Stability Analysis}

Stability analysis of optimized preparation (GZMS1) was conducted according to the ICH guidelines. Sampling was made to check their residual drug content, particle size, zeta potential and physical appearance at the interval of $0,45,90$ and 180 days. Detailed results of the stability study were shown in Table 4 . Result stated that the GZ-MS1 was more stable at 25 $\pm 2^{\circ} \mathrm{C}$ when compared with higher temperatures. The rate of degradation (first order) was increased when the temperature was increased due to loss of $\%$ drug residual content of the formulation. A plot of $(\log \mathrm{K})$ values versus the reciprocal temperature $\left(1 / \mathrm{T} \times 10^{-3}\right)$ was found to be linear in the selected temperature range (25-

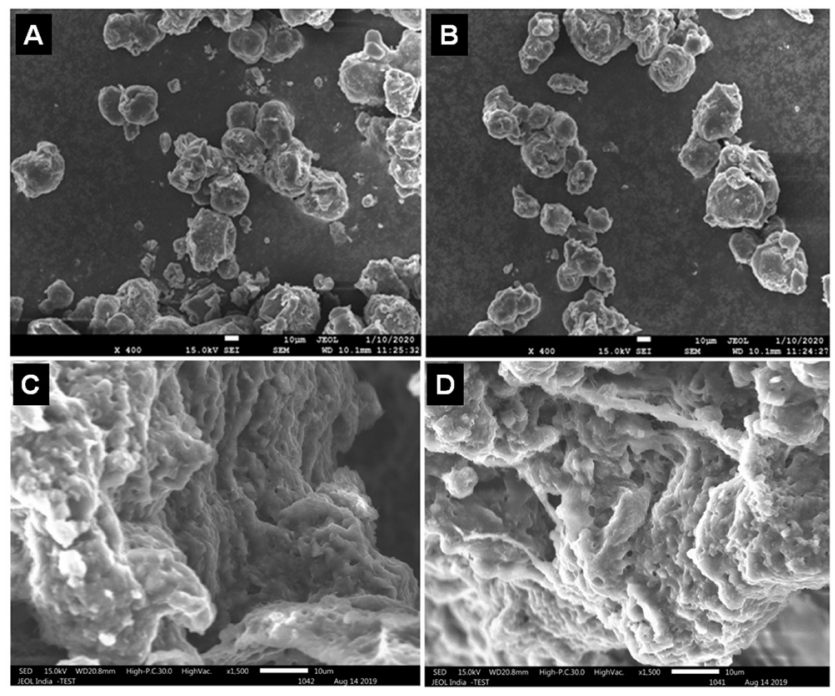

Figure 5: SEM photomicrographs of GZ-MS1 at 400x (A), placebo formulation at $400 x(B)$, GZ-MS1 at $1500 x$ (C) and placebo formulation at $1500 \times$ (D). $\left.40^{\circ} \mathrm{C}\right)$. First order and Arrhenius plot of the GZ-MS1 for degradation at $25^{\circ} \mathrm{C}\left(r^{2}=0.8624\right), 30^{\circ} \mathrm{C}\left(r^{2}=0.9970\right)$ and $40^{\circ} \mathrm{C}\left(r^{2}=0.9916\right)$ were represented in Figure 6(A,B) respectively. Shelf-life $\left(\mathrm{T}_{90}\right)$ of GZ-MS1 at 25, 30 and $40^{\circ} \mathrm{C}, \mathrm{GZ}-\mathrm{MS} 1$ was found to be $3.79,2.87$ and 1.17 years respectively.

\section{Antioxidant Marker Enzymes Estimation in Rat Gastric Tissue}

The levels of rat gastric antioxidant markers were elevated more in group II as compared with the normal group $\left({ }^{* * *} P<0.001\right)$ which has been shown in Figure 7. The improved levels of gastric antioxidant enzyme systems like CAT, SOD and GPx were significantly achieved with test group III $\left({ }^{* *} P<0.05\right)$ and group IV $\left({ }^{* *} P<0.001\right)$ when compared to disease control. In case of TBRAS, its altered level was reduced significantly with GZ200 $\left({ }^{* *} P<0.05\right)$ and GZ-MS1 group $\left({ }^{* * *} P<\right.$ $0.001)$ in comparison with group II. But the placebo group did not produce any significant effect on the antioxidant enzyme systems of stomach as compared with group II which may be due to the absence of an active moiety (GZ) in the formulation. The detail results were represented graphically in Figure 7(A-D).
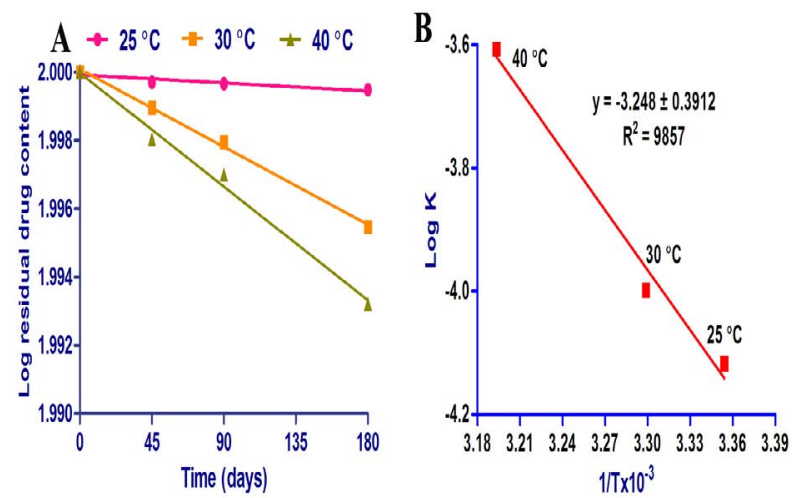

Figure 6: First order (A) and Arrhenius plot (B) of GZ-MS1 for degradation at different storage temperatures $\left(25^{\circ} \mathrm{C}, 30^{\circ} \mathrm{C}\right.$ and $40^{\circ} \mathrm{C}$ ).

\begin{tabular}{|c|c|c|c|c|c|c|c|c|}
\hline \multicolumn{9}{|c|}{ Table 3: Kinetic models of various formulations, GZ-MS1-3. } \\
\hline \multirow{2}{*}{ Formulations } & \multicolumn{2}{|c|}{ Zero order } & \multicolumn{2}{c|}{ First order } & \multicolumn{2}{c|}{$\begin{array}{c}\text { Higuchi square } \\
\text { root }\end{array}$} & \multicolumn{2}{c|}{ Korsmeyer peppas } \\
\cline { 2 - 9 } & $\mathbf{r}^{2}$ & $\mathbf{K}$ & $\mathbf{r}^{2}$ & $\mathbf{K}$ & $\mathbf{r}^{2}$ & $\mathbf{K}$ & $\mathbf{r}^{2}$ & $\mathbf{n}$ \\
\hline GZ-MS1 & 0.940 & 4.376 & 0.970 & 0.050 & 0.941 & 22.32 & 0.907 & 1.127 \\
\hline GZ-MS2 & 0.949 & 4.005 & 0.985 & 0.036 & 0.936 & 20.29 & 0.935 & 1.173 \\
\hline GZ-MS3 & 0.961 & 3.648 & 0.988 & 0.028 & 0.931 & 18.31 & 0.963 & 1.25 \\
\hline
\end{tabular}




\section{DISCUSSION}

Emulsification-cross linking technique was used to develop glycyrrhizin-loaded different formulations, GZ-MS1-3 due to its simplicity, reproducibility and ease of handling. Based on GZ and a polymer ratio (1:10-1:16 w/w), GZ-MS1-3 was prepared for gastric delivery against PU. Tiny particle size and negative zeta potential was attributed towards GZ-MS1 which may be due to uniform distribution of particles $(0.62 \pm 0.11$ PDI) with a suitable drug and polymer ratio. The less PDI indicates the homogeneity of the system. ${ }^{31}$ When the drug-polymer concentrations were increasing, the
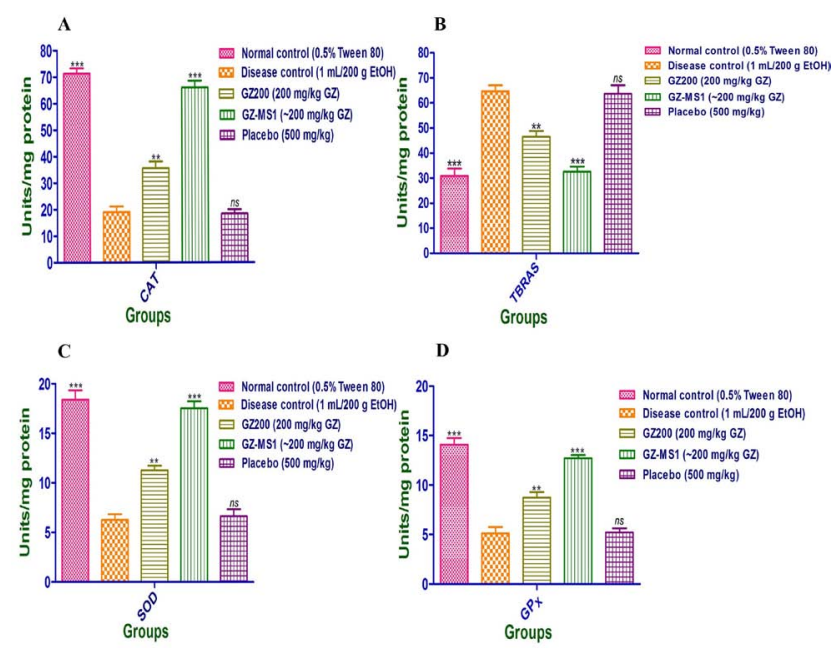

Figure 7: Effect of GZ loaded mucoadhesive formulation on various gastric antioxidant enzyme levels (A) CAT, (B) TBARS, (C) SOD and (D) GPX. Values were shown as Mean \pm SEM ( $n$ $=6)$. $P$ value $\left({ }^{* \star} P<0.05\right.$ and $\left.{ }^{* \star *} P<0.001\right)$ as compared to the normal and disease control group. characteristics (particle size, zeta potential and PDI) of the formulations (GZ-MS2 and GZ-MS3) were also increased. High $\% \mathrm{EE}$ was credited to the optimized formulation, GZ-MS1, which may be due to its smaller particle size than the others.

GZ-MS1 exhibited a significant degree of swelling and mucoadhesive property at $\mathrm{pH} 1.2$ (SGF) when compared with other formulations. The mucoadhesiveness with stomach lining containing glycoproteins (mucins) favors controlled release of the formulation and helps in retaining it for longer periods. Mucoadhesion offers electrostatic interaction that includes Vander Waal forces and hydrogen bonding between mucin network and bioadhesive polymers. ${ }^{32-35}$

The in vitro dissolution study was performed for 24 $h$ to ensure the sustained release properties of the developed mucoadhesive delivery systems. The order of drug release of the different formulations (GZ-MS13) were obtained in the sequence of GZ-MS1>GZMS2>GZ-MS3. GZ-MS1 showed more sustained release profile for $24 \mathrm{~h}$ in comparison with GZ-MS2 and GZ-MS3 which may be due to the smaller particle size and greater mucoadhesive efficiency. The GZ-MS1 expressed its release kinetic in a non-Fickian pattern (super Case-II transport mechanism). These could be due to matrix erosion and the diffusion of the formulation. ${ }^{36}$

Stability study indicated that GZ-MS1 was more stable at the room environment $\left(25^{\circ} \mathrm{C}\right)$ rather than the elevated temperature because when the storage temperature was changed towards higher temperature $\left(40^{\circ} \mathrm{C}\right)$, their zeta potential was also changed. Products stability was linked

\begin{tabular}{|c|c|c|c|c|c|}
\hline Temperature & $\begin{array}{l}\text { Periods } \\
\text { (in days) }\end{array}$ & $\begin{array}{l}\text { \%Residual } \\
\text { drug content }\end{array}$ & $\begin{array}{l}\text { Log residual } \\
\text { drug content }\end{array}$ & $\begin{array}{c}\text { Particle size } \\
(\mu \mathrm{m})\end{array}$ & $\begin{array}{c}\text { Zeta } \\
\text { potential } \\
(\mathrm{mV})\end{array}$ \\
\hline \multirow{4}{*}{$\begin{array}{c}25 \pm 2^{\circ} \mathrm{C} / 60 \pm 5 \% \\
\mathrm{RH}\end{array}$} & 0 & 100 & 2 & $50.18 \pm 1.15$ & $-31.15 \pm 2.16$ \\
\hline & 45 & 99.93 & 1.99969 & $50.56 \pm 1.20$ & $-31.67 \pm 1.98$ \\
\hline & 90 & 99.92 & 1.99965 & $51.85 \pm 1.33$ & $-31.90 \pm 1.36$ \\
\hline & 180 & 99.88 & 1.99947 & $52.14 \pm 2.10$ & $-32.81 \pm 1.11$ \\
\hline \multirow{4}{*}{$\begin{array}{c}30 \pm 2^{\circ} \mathrm{C} / 75 \pm 5 \% \\
\mathrm{RH}\end{array}$} & 0 & 100 & 2 & $50.18 \pm 1.15$ & $-31.15 \pm 2.16$ \\
\hline & 45 & 99.76 & 1.99895 & $51.75 \pm 1.84$ & $-31.85 \pm 2.45$ \\
\hline & 90 & 99.53 & 1.99795 & $52.28 \pm 2.11$ & $-32.98 \pm 1.78$ \\
\hline & 180 & 98.46 & 1.99325 & $53.95 \pm 2.18$ & $-33.08 \pm 1.12$ \\
\hline \multirow{4}{*}{$\begin{array}{c}40 \pm 2^{\circ} \mathrm{C} / 75 \pm 5 \% \\
\mathrm{RH}\end{array}$} & 0 & 100 & 2 & $50.18 \pm 1.15$ & $-31.15 \pm 2.16$ \\
\hline & 45 & 99.55 & 1.99804 & $52.66 \pm 2.45$ & $-36.35 \pm 1.21$ \\
\hline & 90 & 98.31 & 1.99699 & $58.74 \pm 1.86$ & $-38.64 \pm 1.77$ \\
\hline & 180 & 97.45 & 1.99321 & $65.18 \pm 1.53$ & $-41.30 \pm 1.56$ \\
\hline
\end{tabular}


with their zeta potential; result stated that negative zeta value was attributed for GZ-MS1 which sustains its stability for longer storage conditions. Zeta potential could be a major stability factor for the formulations. ${ }^{37}$ The pure glycyrrhizin (GZ200) exhibited less antioxidant potential through different gastric enzymes as compared with GZ-MS1. GZ-MS1 exhibited improved antioxidant potential which may be due to its enhanced gastric absorption..$^{38}$ Hence, glycyrrhizin loaded mucoadhesive microspheres could be promising for gastric delivery.

\section{CONCLUSION}

The oral controlled release system of GZ was developed with carbohydrate polymers (SA and GG). The optimized GZ-mucoadhesive microspheres exhibited enhanced drug absorption and gastroprotection effect, which might be due to its potent antioxidant potential against oxidative stress induced by ethanol. The GZ-MS1 was found to be an effective, stable and safe for oral delivery. It significantly restores the altered level of various gastric antioxidant enzymes in ethanol induced oxidative stress. Thus, the SA-GG based GZ loaded mucoadhesive microspheres could be explored further as a promising carrier for the treatment of PU.

\section{ACKNOWLEDGEMENT}

Authors are thankful to the Prof. Vishal Trivedi, IIT Guwahati, India for helping in SEM analysis of the samples. Authors also want to extend their deep gratitude to Prof. Anoop K. Gupta, Dean Academics, GLA University, Mathura for his kind encouragement and moral support for the research activity.

\section{CONFLICT OF INTEREST}

The authors declare no conflict of interest.

\section{ABBREVIATIONS}

CAT: Catalase; EE: Entrapment Efficiency; FTIR: Fourier Transforms Infrared; GPx: Glutathione Peroxidase; GZ: Glycyrrhizin; GZ-MS: GZ Loaded Microspheres; ICH: International Conference on Hormonization; PU: Peptic Ulcer; SEM: Surface Electron Microscopy; SGF: Simulated Gastric Fluid; SOD: Superoxide Dismutase; TBRAS: Thiobarbituric Acid Reactive Substances.

\section{REFERENCES}

1. Kim BW. Diagnosis and treatment of peptic ulcer disease: Present and future perspective. Korean J Gastroenterol. 2016;67(6):318-20.
2. Yu JX, Russell WA, Asokkumar R, Kaltenbach T, Soetikno R. Clipping over the scope for recurrent peptic ulcer bleeding is cost-effective as compared to standard therapy: An initial assessment. Gastrointest Endosc Clin N Am. 2020;30(1):91-7.

3. Ahmad AA, Kasim KF, Ma'Radzi AH, Gopinath SCB. Peptic ulcer: Current prospects of diagnostic and nanobiotechnological trends on pathogenicity. Process Biochem. 2019;85:51-9.

4. Ragab TI, Awdan ESA, El-Bassyouni GT, Salama BM, Helmy WA, Esawy MA. Role of levan extracted from bacterial honey isolates in curing peptic ulcer: In vivo. Int J Biol Macromol. 2020;142:564-73.

5. Tourani M, Habibzadeh M, Karkhah A, Shokri-Shirvani J, Barari L, Nouri HR. Association of TNF- $\alpha$ but not IL-1 $\beta$ levels with the presence of Helicobacter pylori infection increased the risk of peptic ulcer development. Cytokine. 2018;110:232-6.

6. Bagheri N, Razavi A, Pourgheysari B, Azadegan-Dehkordi F, Rahimian G, Pirayesh A, et al. Up-regulated Th17 cell function is associated with increased peptic ulcer disease in Helicobacter pylori-infection. Infect Genet Evol. 2018;60:117-25.

7. Awaad AS, El-Meligy RM, Soliman GA. Natural products in treatment of ulcerative colitis and peptic ulcer. J Saudi Chem. Soc. 2013;17(1):101-24.

8. Harwansh R, Patra K. Pharmacological studies on Glycyrrhiza glabra. Pharmacologyonline. 2011;2:132-8.

9. Jalilzadeh-Amin G, Najarnezhad V, Anassori E, Mostafavi M, Keshipour H. Antiulcer properties of Glycyrrhiza glabra L. extract on experimental models of gastric ulcer in mice. Iran J Pharm Res. 2015;14(4):1163-70.

10. Bernela M, Ahuja M, Thakur R. Enhancement of anti-inflammatory activity of glycyrrhizic acid by encapsulation in chitosan-katira gum nanoparticles. Eur J Pharm Biopharm. 2016;105:141-7.

11. Takeda S, Ishihara K, Wakui Y, Amagaya S, Maruno M, Akao T, et al. Bioavailability study of glycyrrhetic acid after oral administration of glycyrrhizin in rats; relevance to the intestinal bacterial hydrolysis. J Pharm Pharmacol. 1996;48(9):902-5.

12. Rani R, Dahiya S, Dhingra D, Dilbaghi N, Kim KH, Kumar S. Evaluation of anti-diabetic activity of glycyrrhizin-loaded nanoparticles in nicotinamidestreptozotocin-induced diabetic rats. Eur J Pharm Sci. 2017;106:220-30.

13. Streubel A, Siepmann J, Bodmeier R. Drug delivery to the upper small intestine window using gastroretentive technologies. Curr Opin Pharmacol. 2006;6(5):501-8.

14. Harwansh RK, Deshmukh R, Rahman MA. Nanoemulsion: Promising nanocarrier system for delivery of herbal bioactives. J Drug Delivery Sci Technol. 2019;51:224-33.

15. Mukherjee PK, Harwansh RK, Bhattacharyya S. Bioavailability of herbal products: Approach toward improved pharmacokinetics. Evidence-based Validation of Herbal Medicine. Elsevier: USA; 2015;217-45.

16. Klausner EA, Lavy E, Friedman M, Hoffman A. Expandable gastroretentive dosage forms. J Control Release. 2003;90(2):143-62.

17. Malik RK, Malik P, Gulati N, Nagaich U. Fabrication and in vitro evaluation of mucoadhesive ondansetron hydrochloride beads for the management of emesis in chemotherapy. Int J Pharm Investig. 2013;3(1):42-6.

18. Huang $\mathrm{Y}$, Leobandung W, Foss A, Peppas NA. Molecular aspects of muco and bioadhesion: tethered structures and site-specific surfaces. J Control Release. 2000;65(1-2):63-71.

19. Agüero $L$, Zaldivar-Silva D, Peña $L$, Dias ML. Alginate microparticles as oral colon drug delivery device: A review. Carbohydr Polym. 2017;168:32-43.

20. Prajapati V, Bansal M, Sharma PK. Mucoadhesive buccal patches and use of natural polymer in its preparation. Int J Pharm Tech Res. 2012;4(2):582-9.

21. Gaba P, Singh S, Gaba M, Gupta GD. Galactomannan gum coated mucoadhesive microspheres of glipizide for treatment of type 2 diabetes mellitus: In vitro and in vivo evaluation. Saudi Pharm J. 2011;19(3):143-52.

22. George A, Shah PA, Shrivastav PS. Guar gum: Versatile natural polymer for drug delivery applications. Eur Polym J. 2019;112:722-35.

23. Deshmukh R, Harwansh RK, Paul SD, Shukla R. Controlled release of sulfasalazine loaded amidated pectin microparticles through Eudragit $S$ 100 coated capsule for management of inflammatory bowel disease. J Drug Delivery Sci Technol. 2020;55:101495.

24. Malik RK, Malik P, Gulati N, Nagaich U. Fabrication and in vitro evaluation of mucoadhesive ondansetron hydrochloride beads for the management of emesis in chemotherapy. Int J Pharm Investig. 2013;3(1):42-6. 
25. Sidahmed HMA, Vadivelu J, Loke MF, Arbab IA, Abdul B, Sukari MA, et al. Anti-ulcerogenic activity of dentatin from Clausena excavata Burm.F. against ethanol-induced gastric ulcer in rats: Possible role of mucus and anti-oxidant effect. Phytomedicine. 2019;55:31-9.

26. Beers RFJr, Sizer IW. A spectrophotometric method for measuring the breakdown of hydrogen peroxide by catalase. J Biol Chem. 1952;195(1):13340.

27. Ohkawa $\mathrm{H}$, Ohishi $\mathrm{N}$, Yagi K. Assay for lipid peroxides in animal tissues by thiobarbituric acid reaction. Anal Biochem. 1979;95(2):351-8.

28. Kakkar P, Das B, Viswanathan PN. A modified spectrophotometric assay of superoxide dismutase. Indian J Biochem Biophys. 1984;21(2):130-2.

29. Paglia DE, Valentine WN. Studies on the quantitative and qualitative characterization of erythrocyte glutathione peroxidase. J Lab Clin Med. 1967;70(1):158-69.

30. Lowry $\mathrm{OH}$, Rosebrough NJ, Farr AL, Randall R. Protein measurement with the Folin phenol reagent. J Biol Chem. 1951;193(1):265-75.

31. Danaei M, Dehghankhold M, Ataei S, Davarani FH, Javanmard R, Dokhani $A$, et al. Impact of particle size and polydispersity index on the clinical applications of lipidic nanocarrier systems. Pharmaceutics. 2018;10(2):57.

32. Tao Y, Lu Y, Sun Y, Gu B, Lu W, Pan J. Development of mucoadhesive microspheres of acyclovir with enhanced bioavailability. Int $\mathrm{J}$ Pharm. 2009;378(1-2):30-6
33

Gómez-Santos L, Alonso E, Díaz-Flores L, Madrid JF, Sáez FJ. Different glycoconjugate content in mucus secreting cells of the rat fundic gastric glands. Anat Rec. 2018;301(12):2128-44.

34. Harwansh RK, Deshmukh R, Barkat MA, Rahman MA. Bioinspired polymericbased core-shell smart nano-systems. Pharm Nanotechnol. 2019;7(3):181205.

35. Deshmukh R. Bridging the gap of drug delivery in colon cancer: The role of chitosan and pectin based nanocarriers system. Curr Drug Deliv. 2020;17(10):911-24.

36. Cherstvy AG, Thapa S, Wagner CE, Metzler R. Non-Gaussian, nonergodic and non-Fickian diffusion of tracers in mucin hydrogels. Soft Matter. 2019;15(12):2526-51.

37. Harwansh RK, Mukherjee PK, Bahadur S, Biswas R. Enhanced permeability of ferulic acid loaded nanoemulsion based gel through skin against UVA mediated oxidative stress. Life Sci. 2015;141:202-11.

38. Cheng YT, Lu CC, Yen GC. Phytochemicals enhance antioxidant enzyme expression to protect against NSAID-induced oxidative damage of the gastrointestinal mucosa. Mol Nutr Food Res. 2017;61(6):10. 1002/ mnfr.201600659.

\section{PICTORIAL ABSTRACT}

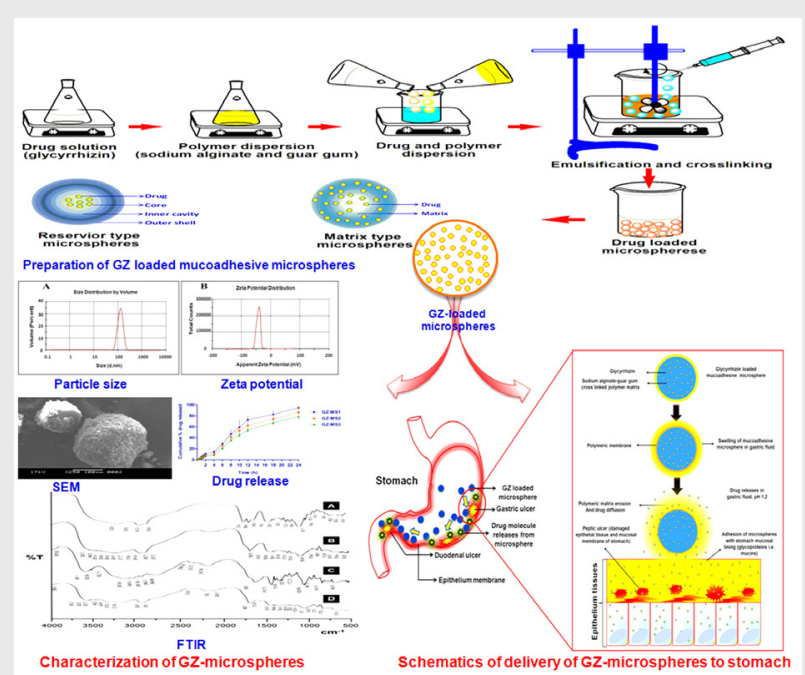

\section{SUMMARY}

Glycyrrhizin (GZ) is reported for its antioxidant and gastroprotection potential but its therapeutic efficacy is limited due to low absorption, short half-life and poor bioavailability. Aim of the current study was to formulate sodium alginate and guar gum based GZ loaded mucoadhesive microspheres for the management of peptic ulcer. GZ loaded microspheres (GZ-MS1-3) were prepared by an emulsification-crosslinking technique. Suitable particle size, zeta potential, significant swelling index, mucoadhesive efficiency and maximum drug release profile in simulated gastric fluid (SGF, $\mathrm{pH}$ 1.2) was achieved with GZ-MS1. FTIR confirmed that there was no any interaction observed between $\mathrm{GZ}$ and excipients. The reduced levels of gastric antioxidant enzymes (catalase, thiobarbituric acid reactive substances, superoxide dismutase and glutathione peroxidase) with respect to the normal group were improved significantly by GZ-MS1 against ethanolmediated oxidative stress $\left({ }^{*} P<0.05\right.$ and ${ }^{*}{ }^{*} P<$ $0.001)$. Thus, the mucoadhesive microspheres of $G Z$ could be an effective strategy for the management of peptic ulcer.

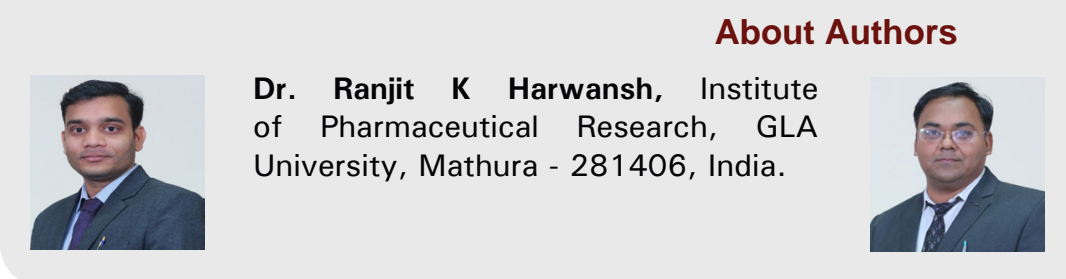

Dr. Rohitas Deshmukh, M. Pharm, Ph.D. Associate Professor Institute of Pharmaceutical Research, GLA University, Mathura -281406, India.

Cite this article: Harwansh RK, Deshmukh R. Formulation and Evaluation of Sodium Alginate and Guar Gum Based Glycyrrhizin Loaded Mucoadhesive Microspheres for Management of Peptic Ulcer. Indian J of Pharmaceutical Education and Research. 2021;55(3):728-37. 